\title{
PERANCANGAN SISTEM INFORMASI PENGAJUAN DAN PELAPORAN PEMBAYARAN TUNJANGAN KINERJA PADA LEMBAGA PEMASYARAKATAN SALEMBA BERBASIS WEB MENGGUNAKAN SKEMA REST API
}

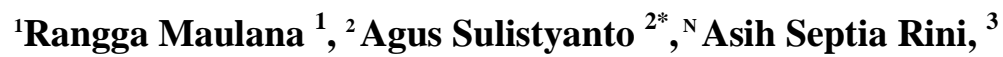 \\ ${ }^{1,2,3}$ Program Studi Sistem Informasi, STMIK Jayakarta \\ Jl. Salemba I No.10, RT.4/RW.6, Kenari, Senen, Jakarta Pusat, Dki Jakarta, Indonesia \\ *e-mail: ranggamaulana71@gmail.com,agus.sulistyanto@gmail.com, \\ asihseptiarini@stmik.jayakarta.ac.id
}

Received: 2021-07-29, Revised: 2021-08-11, Accepted: 2021-08-22

\section{Abstrak}

Tujuan dari penelitian ini adalah membangun perancangan sistem informasi bidang keuangan untuk mengoptimalkan kinerja dan meminimalkan terjadinya kesalahan human error pada saat rekapitulasi data di Lembaga Pemasyarakatan Salemba. Perancangan sistem informasi ini menggunakan metode pengembangan Waterfall, dengan sistem RESTfull API (Application Programming Interface) dimana pengerjaan pada sisi Front End menggunakan library ReactJS, pada sisi Back End menggunakan library Laravel/Lumen, dan database yang digunakan adalah MariaDB. Komunikasi data antara Back End dan Front End menggunakan API (Application Programming Interface) dengan Format JSON (Javascript Object Notation). Pengujian aplikasi menggunakan metode pengujian Black-Box, dimana akan dilakukan pengujian diseluruh fitur aplikasi.

Kata Kunci: Lembaga Pemasyarakatan Salemba, RESTfull API, ReactJS, Laravel, Lumen, MariaDB

\section{Abstract}

The purpose of this research is to develop a financial information system design to optimize performance and minimize the occurrence of human errors during data recapitulation at the Salemba Penitentiary. The design of this information system uses the Waterfall development method, with a RESTfull API (Application Programming Interface) system where work on the Front End uses the ReactJS library, on the Back End uses the Laravel/Lumen library, and the database used is MariaDB. Data communication between Back End and Front End uses API (Application Programming Interface) with JSON (Javascript Object Notation) Format. Testing the application using the BlackBox testing method, where testing will be carried out on all application features.

Keywords: Salemba Penitentiary, RESTfull API, ReactJS, Laravel, Lumen, MariaDB

\section{PENDAHULUAN (or Introduction)}

Dalam proses pembayaran tunjangan kinerja di Lembaga Pemasyarakatan Salemba, setiap satuan kerja harus mengajukan permintaan kebutuhan dana secara berjenjang melalui kantor wilayah (kanwil). Demikian juga setelah laporan kinerja dibayarkan, satuan kerja harus 
DOI: $10.52362 /$ jmijayakarta.v1i4.507

mengirimkan data laporan pertanggungjawaban secara berjenjang. Proses pengajuan dan pelaporan tunjangan kinerja ini dilakukan secara manual dengan menggunakan aplikasi Micorsoft Excel.

Permasalahan yang sering terjadi adalah ketika terdapat kesalahan input data pegawai oleh satuan kerja maka pembayaran tunjangan kinerja akan berjalan dengan lambat karena harus dilakukan kembali proses rekapitulasi secara manual. Proses rekapitulasi yang berjenjang juga rawan terjadi kesalahan baik kesalahan input, kesalahan formula excel, atau hide/row coloumn file excel pada data yang tidak diperlukan namun masih terhitung didalam formula, tidak terdapatnya dependensi data pada file excel lainnya. Selain itu, keterlambatan pengajuan pembayaran maupun penyampaian laporan pertanggungjawaban juga menjadi keluhan pegawai di Biro Kepegawaian dan Keuangan Lembaga Pemasyarakatan Salemba.

\section{TINJAUAN LITERATUR (Literature Review)}

\subsection{Sistem Informasi}

Berikut ini adalah beberapa definisi sistem informasi menurut para ahli:

1) Menurut Yakub (2012), sistem informasi merupakan suatu kumpulan dari komponen-komponen dalam organisasi yang berhubungana dengan proses penciptaan aliran informasi.

2) Menurut Ida Nuraida (2008), sistem informasi merupakan perangkat prosedur yang teroganisasi dengan sistematik, bila dilaksanakan akan menyediakan informasi yang dapat dimanfaatkan dalam proses pembuatan keputusan.

3) Sutabri (2005), sistem infomasi adalah suatu sistem di dalam suatu organisasi yang mempertemukan kebutuhan pengolahan transaksi harian yang mendukung fungsi operasi organisasi yang bersifat manajerial dengan kegiatan strategi dari suatu organisasi untuk dapat menyediakan kepada pihak luar tertentu dengan laporan-laporan yang diperlukan.

Berdasarkan definisi dari beberapa ahli tersebut, maka dapat disimpulkan bahwa sistem informasi adalah suatu alat untuk menyajikan informasi dengan sedemikian rupa yang digunakan untuk memberikan manfaat kepada pengguna. Dalam penelitian ini sistem informasi bertujuan untuk menyajikan informasi pengajuan dan pelaporan pembayaran tunjangan kinerja dengan informasi yang akurat, tepat waktu, dan relevan.

2.2. Unified modelling Language (UML)

Verdi Yasin (2012:194) dalam bukunya yang berjudul Rekayasa Perangkat Lunak Berorientasi Objek menyatakan: "Unified Modelling Language (UML) adalah sebuah bahasa yang telah menjadi standar dalam industri untuk visualisasi, merancang dan mendokumentasikan sistem piranti lunak. UML menawarkan sebuah standar untuk merancang model sebuah sistem". Sedangkan Menurut Herlawati dan Widodo (2011:10), UML merupakan singkatan dari "Unified Modelling Language" adalah suatu bahasa yang sudah menjadi standar pada visualisasi, perancangan dan juga pendokumentasian sistem software.

2.3. NodeJS

Node.js merupakan salah satu platform pengembang yang digunakan untuk membuat aplikasi berbasis Cloud. Node.js dikembangkan dari bahasa pemprograman JavaScript. Node.js memiliki fitur built-in HTTP server library yang membuatnya mampu menjadi sebuah web server tanpa bantuan software lainnya seperti Apache dan Nginx. 
DOI: $10.52362 /$ jmijayakarta.v1i4.507

Pada dasarnya, Node.js adalah sebuah runtime environment dan script library. Sebuah runtime environment adalah sebuah software yang berfungsi untuk mengeksekusi, menjalankan dan mengimplementasikan fungsi-fungsi serta cara kerja inti dari suatu bahasa pemrograman. Sedangkan script library adalah kumpulan, kompilasi atau bank data berisi skrip/kode-kode pemrograman.

Pada penelitian ini penulis menggunakan NodeJS agar dapat menjalankan library ReactJS, karena skrip ReactJS terdapat di dalam NodeJS.

\subsection{ReactJS}

ReactJS adalah salah satu dari ribuan library yang terdapat didalam NodeJS yang digunakan untuk membangun user interface atau sebuah tampilan website. ReactJS digunakan untuk membangun aplikasi berbasis website. ReactJS. ReactJS bersifat clientserver karena merupakan javasript library.

ReactJS menggunakan konsep modular. Untuk membuat aplikasi skala besar maka pengguna ReactJS dapat membuatnya dengan skala lebih kecil yang nantinya akan disatukan menjadi aplikasi utuh dan dapat digunakan kembali untuk pengembangan aplikasi lainnya.

2.5. PHP

PHP adalah salah satu Bahasa pemrograman script bersifat open-source yang bekerja pada sisi server. PHP digunakan untuk memprogram situs website. Dalam penelitian ini penulis menggunakan PHP untuk membuat sebuah application programming interface (API) yang digunakan untuk melakukan komunikasi antara client dengan server dimana user interface terbuat dengan menggunakan ReactJS dan melakukan komunikasi dengan server.

2.6. MariaDB

MariaDB adalah sebuah implementasi dari sistem manajemen basis data relasional (RDBMS) yang didistribusikan secara gratis dibawah Lisensi GPL (General Public Licence). Setiap pengguna dapat secara bebas menggunakan MariaDB, namun dengan batasan perangkat lunak tersebut tidak boleh dijadikan produk keturunan yang bersifat komersial. MariaDB dikembangkan dari MySQL dimana dipastikan bahwa fungsi-fungsi MySQL dapat berjalan pada umumnya di MariaDB.

2.7. Web Service

Web service merupakan kumpulan suatu layanan berbasis web dengan menggunakan jaringan protokol HTTP, layanan tersebut dapat diakses dan dimanfaatkan oleh pengguna dengan bahasa pemrograman, arsitektur dan sistem operasi yang berbeda (interoperability). Web service harus bersifat stateless, sehingga dapat dibaca dan di akses multi-platform. Arsitektur pada web service dapat dibangun menggunakan Simple Object Access Protocol (SOAP) atau Representational State Transfer (REST), sementara service tersebut direpresentasikan dalam bentuk format teks, JSON atau XML. Pada umumnya formatnya menggunakan JSON dan XML Pada penelitian ini penulis membangun sistem informasi dengan Arsitektur Representational State Transfer (REST) dan format JSON.

2.8. REST

Representational State Transfer yang disingkat REST yang merupakan gaya arsitektur untuk penerapan web service dalam menerapkan konsep perpindahan antar state. Keuntungan interaksi berbasis REST menggunakan Hypertext Transfer Protocol (HTTP) internet yang merupakan hal yang sudah umum digunakan atau memiliki standarisasi secara internasional.

Contoh dari standarisasi ini adalah interaksi berbasis REST semua berkomunikasi status mereka menggunakan kode status HTTP standar. Jadi, 404 berarti sumber daya yang 
DOI: $10.52362 /$ jmijayakarta.v1i4.507

diminta tidak ditemukan; kode 401 berarti permintaan tidak diotorisasi; kode 200 berarti semuanya OK; dan 500 berarti ada kesalahan aplikasi yang tidak dapat dipulihkan pada server.

2.9. Javascript Object Notation (JSON)

Menurut Mitchell (2013:33) JSON adalah kepanjangan dari JavaScript Object Notation. Format JSON mudah untuk dibaca dan ditulis oleh berbagai bahasa scripting.

Struktur JSON, seperti associative array atau object dengan properties di PHP, tanda kurung kurawal $(\{)$ digunakan untuk mengindikasikan level kedalaman yang baru di data struktur. Sedangkan key dan valuenya dipisahkan oleh tanda titik dua ( : ) dan setiap record pada level tertentu akan dipisahkan dengan tanda koma (, ). JSON juga memungkinkan untuk menampilkan list item dengan elegan. JSON memberikan indikasi yang jelas mengenai struktur data dan penyampaian nilai-nilai yang ada di dalamnya, tetapi JSON tidak memberikan informasi spesifik mengenai jenis data yang tepat yang awalnya digunakan.

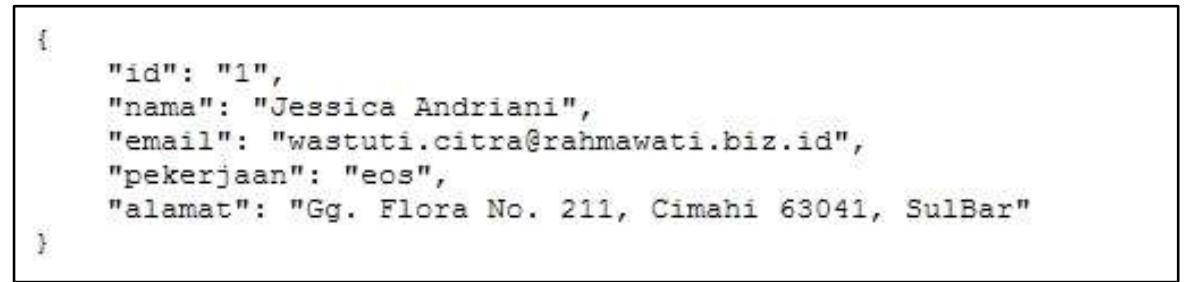

\section{Gambar 2.1 Contoh Format JSON}

\section{METODE PENELITIAN ( Research Method)}

\subsection{Metode Pengumpulan Data}

Metode pengumpulan data pada penelitian yaitu mendapatkan data dengan cara:

a. Metode observasi

Penulis melakukan pengamatan serta analisis seluruh data yang di dapat dari Urusan kepegawaian dan Keuangan. Data yang didapat adalah Lampiran Tunjangan Kinerja Periode Bulan Januari - Februari 2021, Lampiran Tanda Terima Tunjangan Kinerja Pegawai, Lampiran Data Pegawai, Lampiran Tanda Terima Tunjangan Kinerja Pegawai, Lampiran A PMK80, Lampiran Rekapitulasi PPH 21, Surat Pernyataan Tanggungjawab Mutlak, dan Surat Usulan Permintaan Pembayaran Tunjangan Kinerja.

b. Wawancara

Penulis melakukan wawancara secara langsung berupa tanya jawab terhadap pegawai yang menjabat sebagai bagian Keuangan dan Bendahara Pengeluaran.

3.2. Metode Analisis

Metode analisis yang digunakan adalah Object Oriented Analisis. (OOA). OOA melihat masalah berdasarkan objek pengguna sistem. Dengan OOA dapat dibuat pemodelan sistem yang sedang berjalan. Penerapan dari OOA dalam penelitian ini menggunakan diagram Unified Modelling Language (UML).

Diagram Unified Modelling Language (UML) yang penulis gunakan adalah rancangan Use Case Diagram, rancangan Activity Diagram, rancangan Sequence Diagram, dan rancangan Class Diagram.

3.3. Metode Pengembangan

Metode pengembangan aplikasi atau Software Development Life Cycle (SDLC) yang penulis terapkan adalah metode waterfall. Metode waterfall memiliki ciri khusus yaitu 
DOI: $10.52362 / j m i j a y a k a r t a . v 1 i 4.507$

seluruh proses pengembangan dilakukan secara berurutan yang dimulai dari tahap perencanaan konsep, pemodelan, development, pengujian dan pemeliharaan sistem.

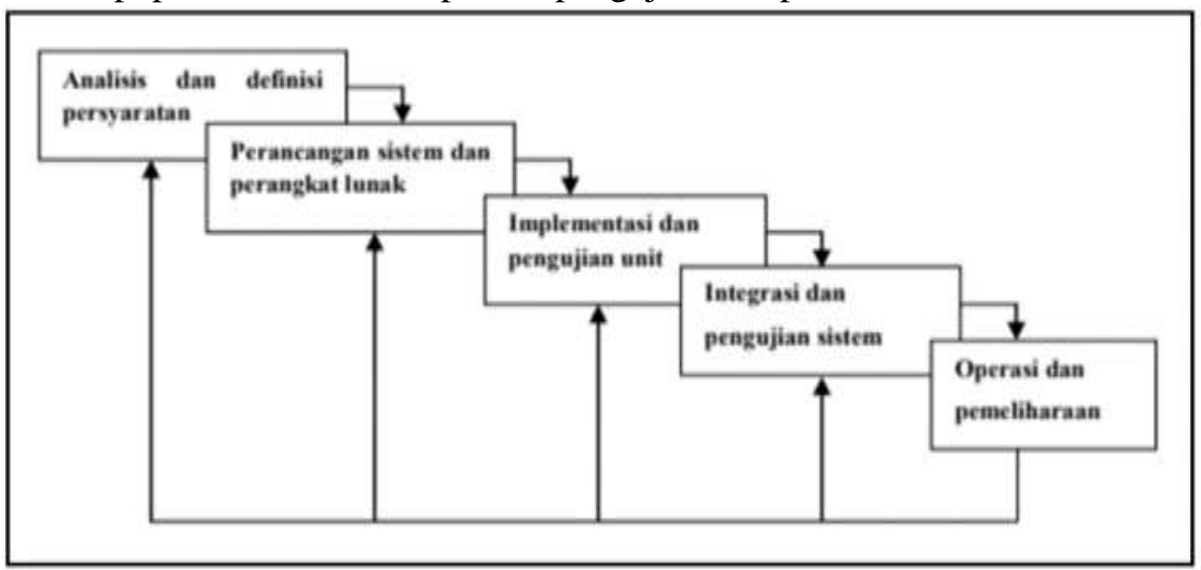

Gambar 3. 1 Model Waterfall

3.4. Metode Perancangan

Metode Perancangan sistem yang digunakan adalah Object Oriented Design (OOD). OOD dilakukan berdasarkan hasil analisa OOA. Pada tahap ini dilakukan penentuan arsitektur sistem, kebutuhan perangkat lunak dan perangkat keras, perancangan database sistem dan perancangan interface sistem.

3.5. Metode Pengujian

Metode pengujian sistem pada penelitian ini menggunakan metode Black-box testing. Menurut Pressman (2010) Black-box testing adalah proses pengujian yang berfokus requirement (persyaratan) fungsional dari perangkat lunak. Black-box testing memungkinkan developer untuk mendapatkan set kondisi input yang sepenuhnya melaksanakan semua requirement (persyaratan) fungsional suatu program (perangkat lunak). Black-box testing berupaya untuk menemukan error dengan kategori:
a. Fungsi yang tidak benar
b. Kesalahan tampilan
c. Kesalahan struktur data
d. Performance Error

\section{HASIL DAN PEMBAHASAN (Results and Analysis)}

\subsection{Lokasi Penelitian}

Penulis melakukan penelitian ini di Lembaga Pemasyarakatan Salemba yang berlokasi di Jl. Percetakan Negara No.88A, RT.12/RW.4, Rawasari, Kec. Cemp. Putih, Kota Jakarta Pusat, Daerah Khusus Ibukota Jakarta 10570. Dalam proses pembayaran tunjangan kinerja di Lembaga Pemasyarakatan Salemba, setiap satuan kerja harus mengajukan permintaan kebutuhan dana secara berjenjang melalui kantor wilayah. Permasalahan yang sering terjadi adalah ketika terdapat kesalahan input data pegawai oleh satuan kerja maka pembayatan tunjangan kinerja akan berjalan dengan lambat karena harus dilakukan kembali proses rekapitulasi secara manual. Penelitian ini dilakukan selama kurun waktu 2 (dua) bulan dari periode bulan April sampai bulan Mei 2021. 
DOI: $10.52362 /$ jmijayakarta.v1i4.507

\subsection{Rancangan Proses UML}

Rancangan proses Unified Modelling Language (UML) adalah suatu desain sistem atau metode yang digunakan untuk membaca proses yang digunakan oleh peneliti pada saat menyelesaikan masalah di penelitian ini. Penelitian ini penulis menggunakan tiga diagram pada UML yaitu Usecase Diagram, Activity Diagram, dan Sequence Diagram.

a. Use Case Diagram

Penulis membangun usecase diagram yang dapat dilihat pada Gambar 4.1 Terdapat 6 usecase yaitu Login, Upload Tunjangan Kinerja, View Tunjangan Kinerja, Download Dokumen, View Data Pegawai, Logout. Pada Usecase View Tunjangan Kinerja memiliki 3 dependency include yaitu Filter berdasarkan nama pegawai, Filter berdasarkan NIP pegawai, dan Filter berdasarkan Periode Tunjangan. Pada Usecase Download Dokumen memiliki 5 dependency include yaitu Dokumen Tanda Terima Tunjangan Kinerja, Dokumen Rekap PPH21, Lampiran A PMK 80, SPTJM, Surat Usulan Pembayaran Tunjangan. Pada Usecase View Data Pegawai memiliki 3 dependency include yaitu Filter berdasarkan nama pegawai, Filter berdasarkan NIP pegawai, Filter berdasarkan jabatan.

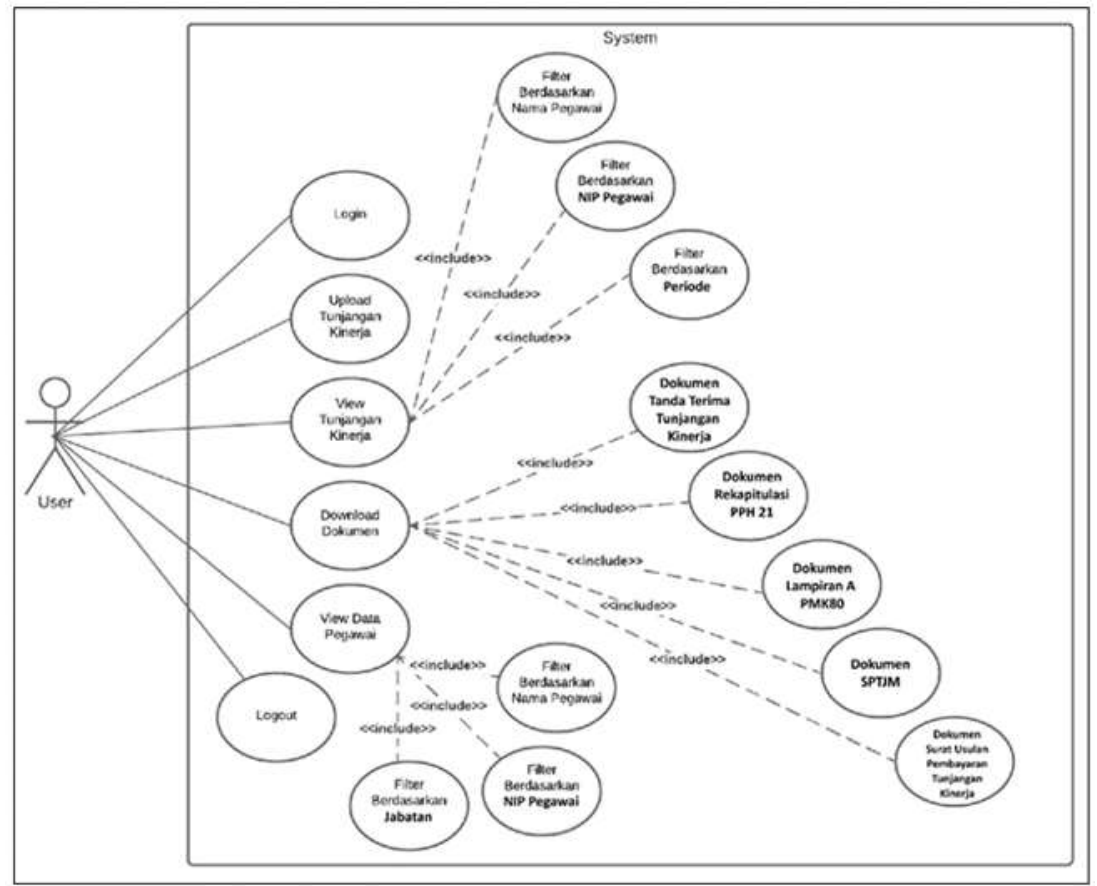

Gambar 4. 1 Use Case Diagram Penelitian

b. Activity Diagram

- Activity Diagram Login

Diagram ini menggambarkan proses pengguna saat memasuki aplikasi dimana pengguna perlu mengisi formulir login yang berisi email dan password. Activity Diagram Login dapat dilihat pada Gambar 4.2 
DOI: $10.52362 /$ jmijayakarta.v1i4.507

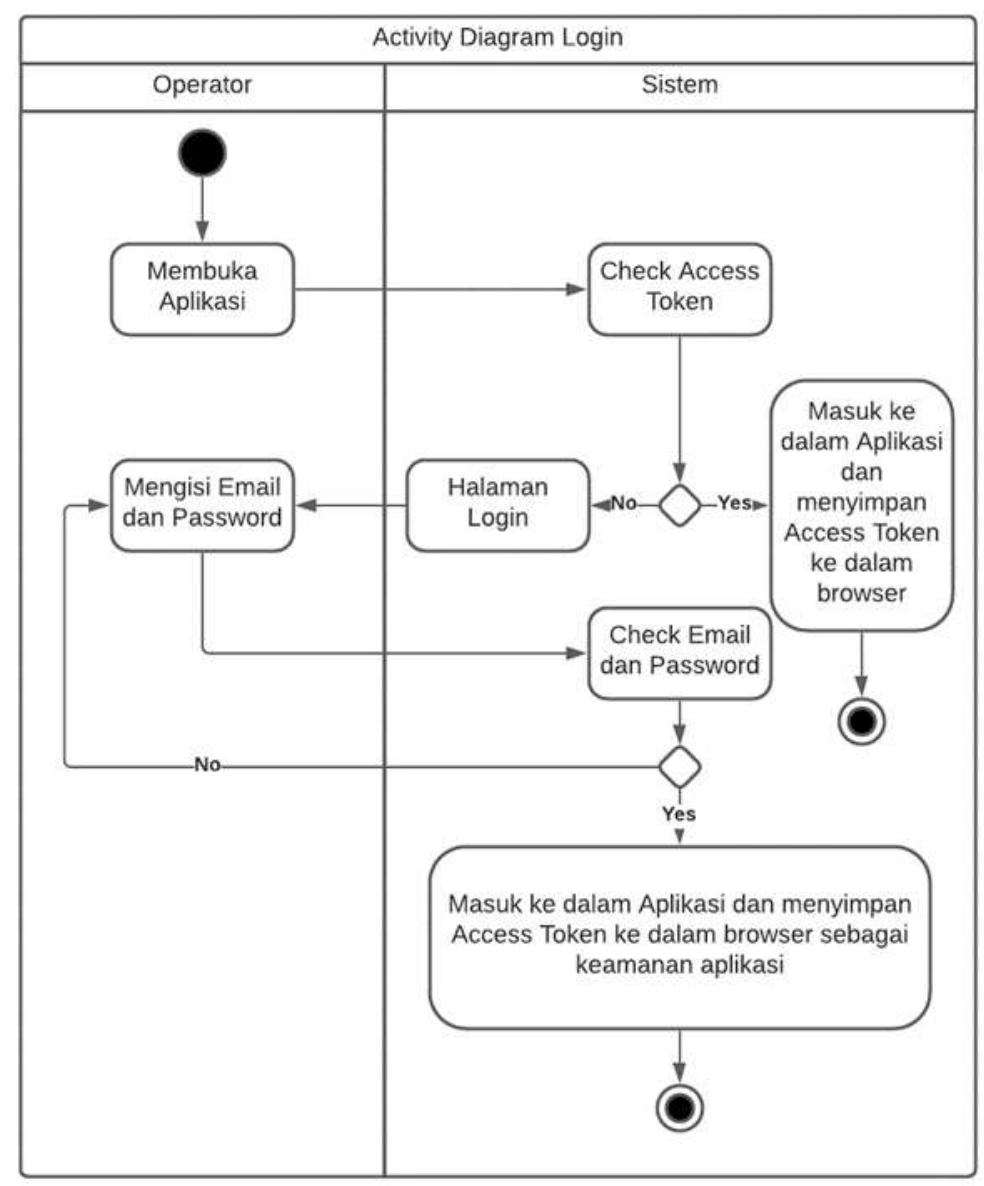

\section{Gambar 4. 2 Activity Diagram Login}

- Activity Diagram Upload Tunjangan Kinerja

Diagram ini menggambarkan proses pengguna saat melakukan upload data tunjangan kinerja ke dalam sistem, dimana pengguna perlu mengisi formulir upload. Activity Diagram Upload Tunjangan Kinerja dapat dilihat pada Gambar 4.3 
DOI: $10.52362 /$ jmijayakarta.v1i4.507

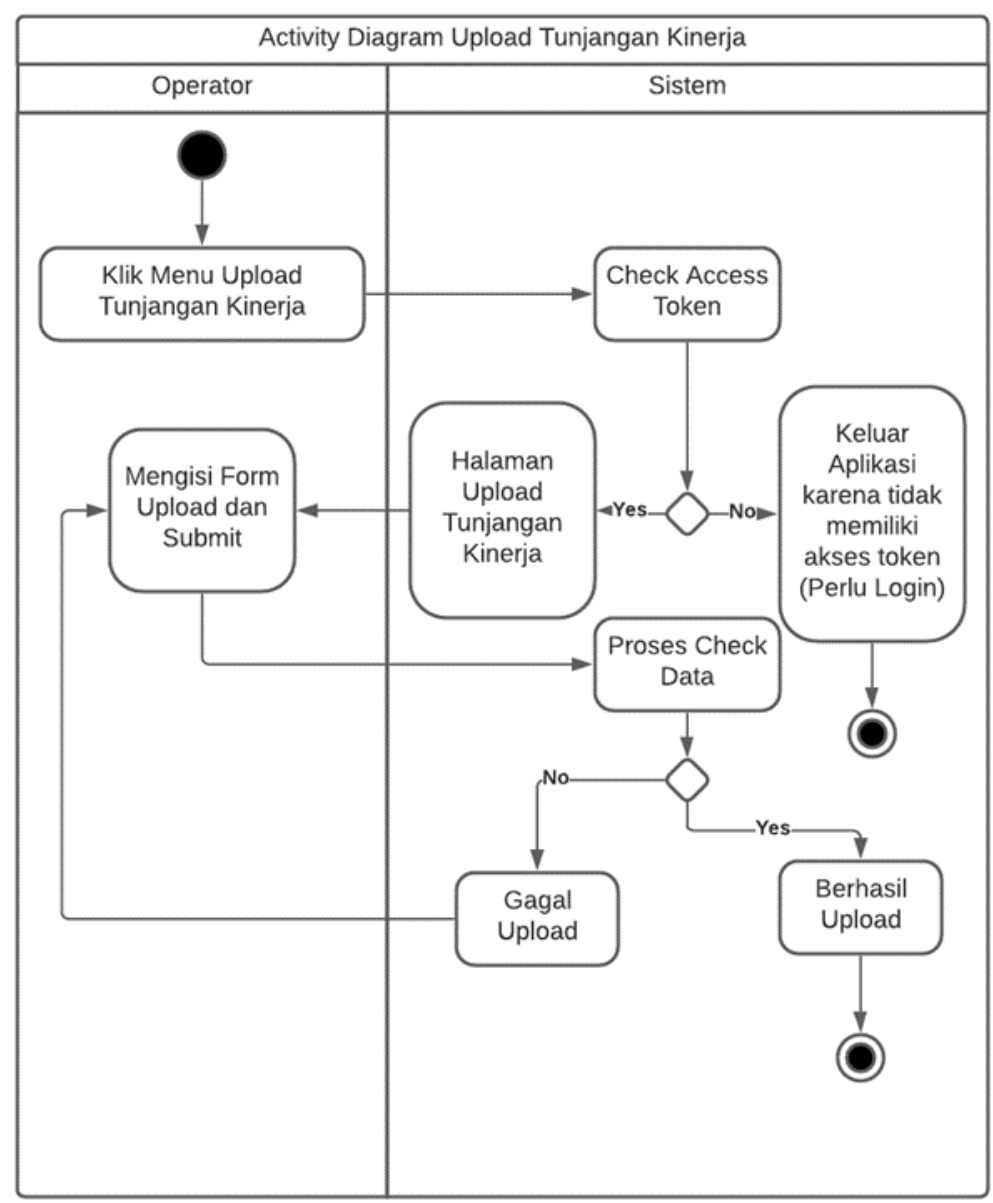

\section{Gambar 4. 3 Activity Diagram Upload Tunjangan Kinerja}

c. Sequence Diagram

- Sequence Diagram Login

Sequence diagram menggambarkan perilaku pada sebuah skenario. Sequence diagram untuk sistem ini merupakaan gambaran proses yang dilakukan pengguna terhadap sistem berdasarkan urutan waktu tertentu.

Sequence Diagram Login menggambarkan proses yang dilakukan pengguna terhadap sistem. Pada saat pengguna mengirimkan email dan password ke dalam sistem. Sistem akan melakukan pengecheckan kesesuaian data email dan password yang terdapat di database sistem. Sequence Diagram Login dapat dilihat pada Gambar 4.4 
DOI: $10.52362 /$ jmijayakarta.v1i4.507

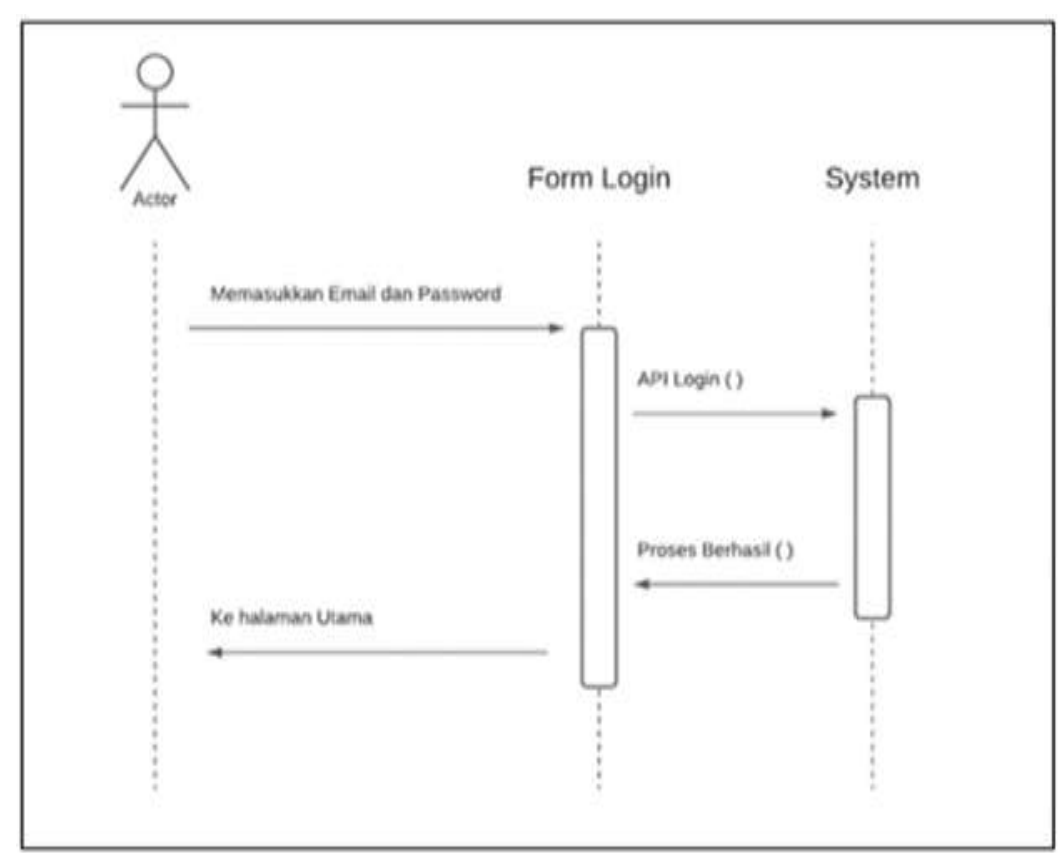

\section{Gambar 4. 4 Sequence Diagram Login}

- Sequence Diagram Upload Tunjangan Kinerja

Sequence Diagram Upload Tunjangan Kinerja menggambarkan proses yang dilakukan pengguna pada saat melakukan Upload File Tunjangan Kinerja. Saat menekan menu Upload Tunjangan Kinerja secara otomatis aplikasi akan mengaktifkan fungsi CheckToken() yang digunakan untuk melakukan verifikasi apakah pengguna terdaftar di basis data. Jika Pengguna terdaftar maka tahap selanjutnya pengguna mengisi Form Upload dan mengirimkannya ke dalam sistem. Sequence Diagram Upload Tunjangan Kinerja dapat dilihat pada Gambar 4.5

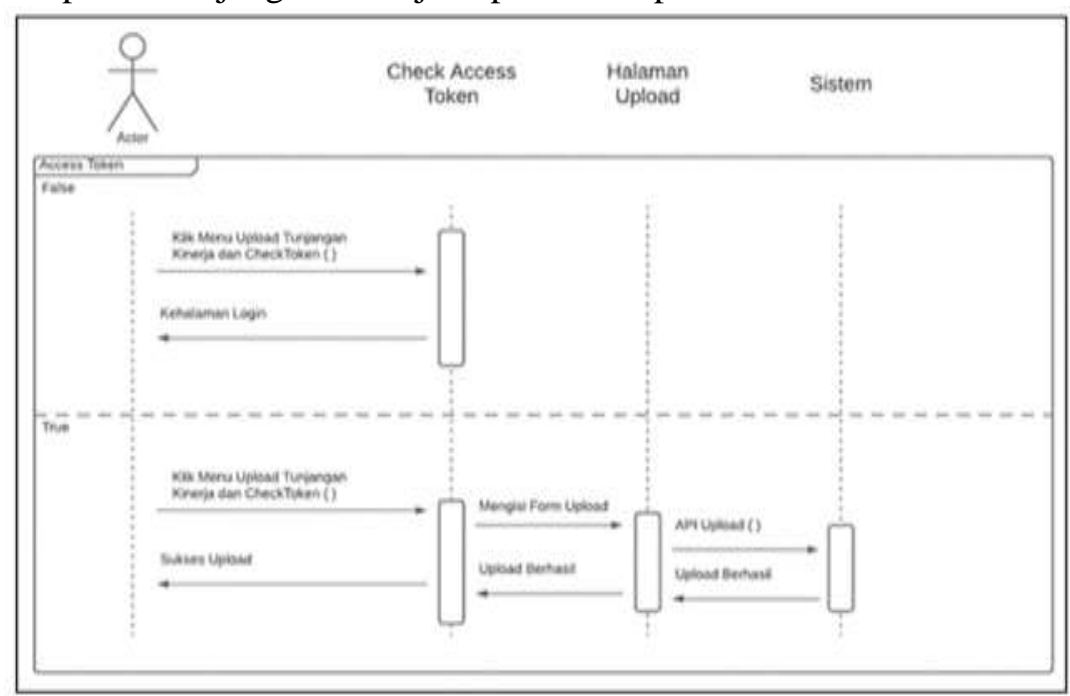

Gambar 4. 5 Sequence Diagram Upload Tunjangan Kinerja

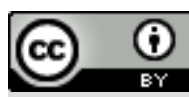

This work is licensed under a Creative Commons Attribution 4.0 International License. 
DOI: $10.52362 /$ jmijayakarta.v1i4.507

d. Class Diagram

Class Diagram pada penelitian ini terdiri dari 4 class yaitu class users, class detail, class period, dan class detail. Pada class users berisi datadata yang digunakan untuk melakukan login ke dalam aplikasi. Pada class detail berisi data-data tunjangan kinerja yang telah di-upload oleh user. Pada class period adalah data periode tiap tunjangan kinerja dan pada class pegawai adalah data-data detail personal pegawai.

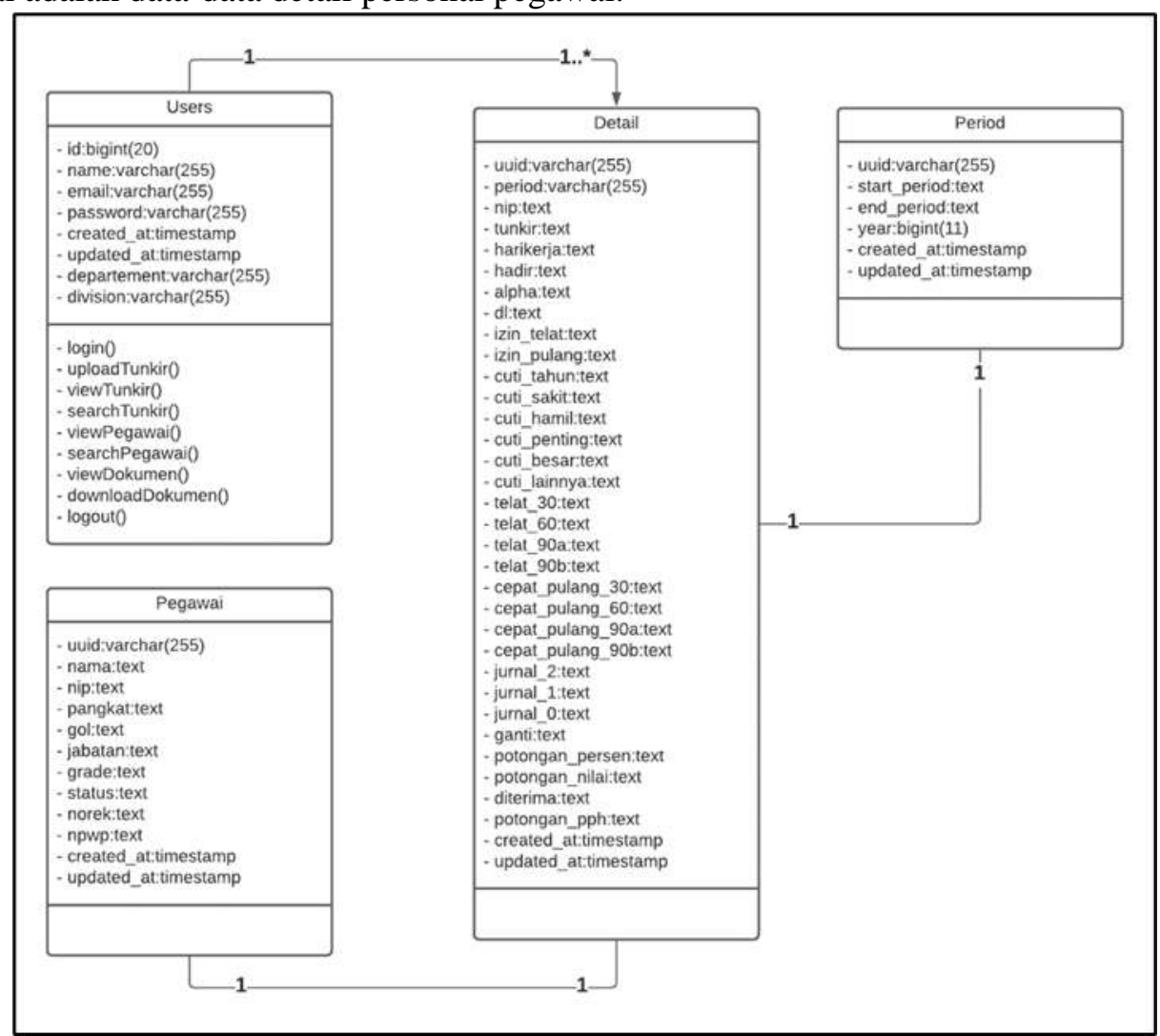

Gambar 4. 6 Class Diagram

4.3. Hasil Penelitian

a. Tampilan Halaman Login
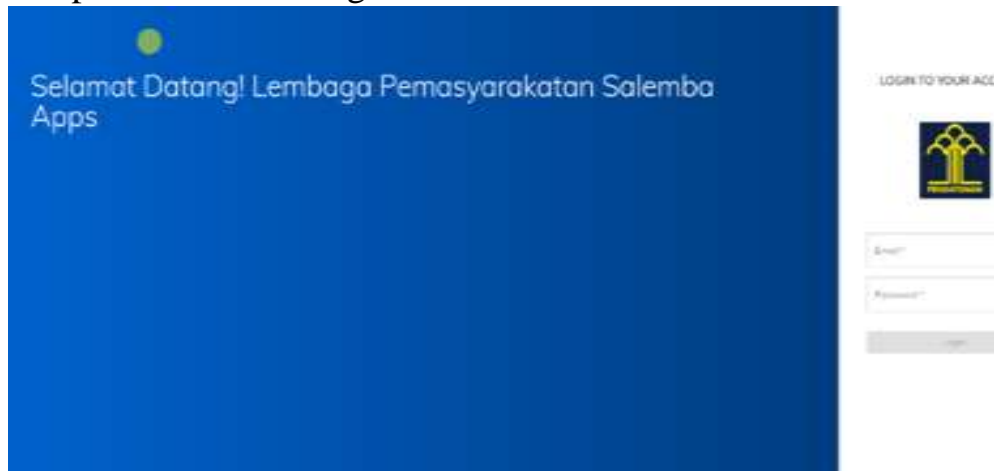

Gambar 4. 7 Tampilan Halaman Login di Website 
DOI: $10.52362 /$ jmijayakarta.v1i4.507

b. Tampilan Halaman Upload Tunjangan Kinerja

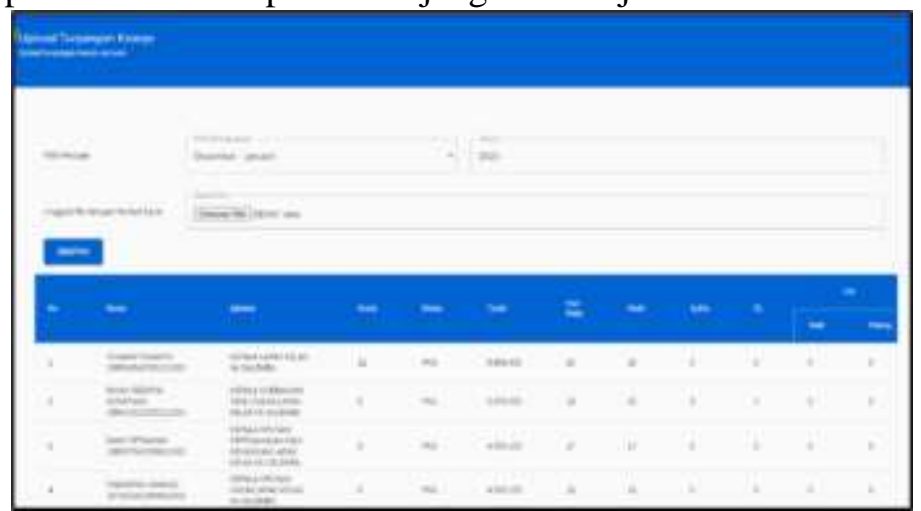

Gambar 4. 8 Tampilan Halaman Upload Tunjangan Kinerja di Website

\section{KESIMPULAN (Conclusion)}

\subsection{Simpulan}

Berdasarkan hasil pembuatan dan pengujian Perancangan Sistem Informasi Pengajuan Dan Pelaporan Pembayaran Tunjangan Kinerja Pada Lembaga Pemasyarakatan Salemba Berbasis Web Menggunakan Skema REST API, maka dapat disimpulkan sebagai berikut:

1. Perancangan sistem informasi ini dapat mempercepat kinerja pegawai Lembaga Pemasyarakatan Salemba dimana dengan hanya melakukan Upload File berupa Excel maka akan langsung dapat men-download 5 jenis dokumen yang diperlukan dalam proses pembayaran tunjangan kinerja.

2. Berdasarkan simpulan pertama maka Perancangan sistem informasi ini dapat meminimalisasi terjadinya Human Error karena proses rekapitulasi secara otomatis dikerjakan oleh sistem.

3. Berdasarkan hasil pengujian yang menggunkan metode pangujian Black Box Testing, baik itu untuk kasus negatif maupun kasus positif, dimana tidak terjadinya kesalahan pada sistem makaa dapat disimpulkan bahwa Perancangan sistem informasi ini berfungsi dengan baik.

5.2. Saran

Berdasarkan hasil implementasi dan pengujian sistem ditemukannya saran - saran pengembangan website yang dapat ditemukannya pada penelitian lebih lanjut yaitu sebagai berikut:

1. Ditambahkannya fungsional website seperti pengubahan data yang memang diperbolehkan untuk diubah.

2. Aplikasi dapat di singkronisasikan dengan aplikasi yang saat ini berjalan dari pihak pemerintah sehingga tidak perlu melakukan proses upload file excel

\section{REFERENSI (Reference)}

[1] Rizal, R., Rahmatulloh, A., Restful Web Service Untuk Integrasi Sistem Akademik Dan Perpustakaan Universitas Perjuangan, Jurnal Ilmiah Informatika vol. 7, no. 01, p. 54-59, 2019. ISSN 2615-1049 
DOI: $10.52362 /$ jmijayakarta.v1i4.507

[2] Yusrizal, D.R., dan Roslidar., Rancang Bangun Layanan Web (Web Service) Untuk Aplikasi Rekam Medis Praktik Pribadi Dokter, Jurnal Online Teknik Elektro vol. 2, no. 01, p. 1-8, 2017. ISSN 2252-7036

[3] Hendri,E., Pengembangan Sistem Pengelolaan Keuangan Sekolah Berbasis Web Dengan Metode Waterfall Pada Smpit Ummi Abiyyi, Cikarang: Sekolah Tinggi Teknologi Pelita Bangsa, 2017

[4] Samantha, D.P., Perancangan Sistem Informasi Pada Toko Sahaaba, Semarang: Universitas Diponegoro, 2011

[5] Nursaid, F., Brata, A., \& Kharisma, A. Pengembangan Sistem Informasi Pengelolaan Persediaan Barang Dengan ReactJS Dan React Native Menggunakan Prototype (Studi Kasus: Toko Uda Fajri). Jurnal Pengembangan Teknologi Informasi dan Ilmu Komputer, vol. 4, no. 1, p. 46-55. 2020. ISSN 2548-964X

[6] Fajrin, R. (2017). Pengembangan Sistem Informasi Geografis Berbasis Node.JS untuk Pemetaan Mesin dan Tracking Engineer dengan Pemanfaatan Geolocation pada PT IBM Indonesia. Jurnal Komputer Terapan ,vol. 3 no. 01, p, 33-40, 2017

[7] Adi Mardian, Thomas Budiman, Rachmawaty Haroen; Verdi Yasin (2021), Perancangan Aplikasi Pemantauan Kinerja Karyawan Berbasis Android di PT. Salestrade Corp. Indonesia. "Jurnal Manajemen Informatika Jayakarta”, E-ISSN : 2797-0930 (Online), P-ISSN :-2746-5985 (Print), Volume 1, Nomor 3,Juli 2021, halaman 169-185, DOI: 10.52362/jmijayakarta.v1i3.481, URL Publikasi: http://journal.stmikjayakarta.ac.id/index.php/JMIJayakarta/article/view/481

[8] Nandang Mulyana, Agus Sulistyanto, Verdi Yasin (2021), Perancangan sistem informasi pengelolaan aset it berbasis web pada pt mandiri axa general insurance, "Jurnal Manajemen Informatika Jayakarta", E-ISSN : 2797-0930 (Online), P-ISSN : 2746-5985 (Print), Volume 1, Nomor 3, Juli 2021, halaman 243-257, DOI: 10.52362/jmijayakarta.v1i3.498 , URL Publikasi: http://journal.stmikjayakarta.ac.id/index.php/JMIJayakarta/article/view/498

[9] Maulia Usnaini, Verdi Yasin, Anton Zulkarnain Sianipar (2021), Perancangan sistem informasi inventarisasi aset berbasis web menggunakan metode waterfall. . "Jurnal Manajemen Informatika Jayakarta", E-ISSN : 2797-0930 (Online), P-ISSN : 2746-5985 (Print) Volume 1, Nomor 1,Februari 2021, halaman 36-55, DOI: 10.52362/jmijayakarta.v1i1.415, URL Publikasi: http://journal.stmikjayakarta.ac.id/index.php/JMIJayakarta/article/view/415

[10] Putri Setiani, Ifan Junaedi, Anton Zulkarnain Sianipar, Verdi Yasin (2021), Perancangan sistem informasi pelayanan penduduk berbasis website di rw 010 Kelurahan Keagungan Kecamatan Tamansari - Jakarta Barat. . "Jurnal Manajemen Informatika Jayakarta”, E-ISSN : 27970930 (Online), P-ISSN : 2746-5985 (Print) Volume 1, Nomor 1,Februari 2021, halaman 20-35, DOI: 10.52362/jmijayakarta.v1i1.414, URL Publikasi:

http://journal.stmikjayakarta.ac.id/index.php/JMIJayakarta/article/view/414 